\title{
COVID-19 Cases and Deaths in India: Epidemiological Lessons and Projections from the Trend
}

\author{
Abhaya Indrayan ${ }^{1}$ \\ ${ }^{1}$ Department of Clinical Research, Max Healthcare, New Delhi, India
}

Address for correspondence Abhaya Indrayan, PhD, FAMS, FRSS, FASc, A-037 Telecom City, B-9/6 Sector 62, Noida 201309, Uttar Pradesh, India (e-mail: a.indrayan@gmail.com).

not enough at present to make projections beyond the third week of May.

An epidemic such as this should be tracked by occurrence of new cases rather than with cumulative cases because cumulative cases can never decline. The trend indicates that we are unlikely to reach to full blown Stage-III of the epidemic so long as precautions such as physical distancing are strictly followed. There is evidence that effective implementation of ban on gathering of five or more with physical distancing and face masks, complete ban on all kinds of transport, malls, cinema halls, parties, etc., can play a decisive role in controlling the spread of infection.

After an erratic pattern, the relative increase in cases per day was the highest, $22 \%$, on 3rd April but it is showing a declining trend since then in percentage terms and is now nearly $6 \%$ on 24 th April, primarily due to continued lockdown. If the opening up of lockdown after 3rd May does not disrupt the present trend and we are able to maintain reduced transmission by physical distancing, the rate of increase can become less than $1 \%$ after the third week of May. The cumulative number of active cases may be nearly 45,000 at that time-others recovered or died. This is the number our medical care facilities should be ready to handle. It seems India is ready to handle that much load on medical care facilities. The present trend indicates that approximately 20\% (nearly 7,000 cases at its peak) of cases will need hospitalization. Cumulative cases will always rise and cannot decline but the new cases after the third week of May could be less than the recoveries and the active cases may decline that would reduce the load on medical care facilities. We hope that the present trend continues, and the projections become a reality.

The trend further indicates that the number of patients reaching to the end point on any given day is nearly the same as the new detections about 2 weeks earlier. The end point is either recovery or death. The mortality is not less than $5 \%$, generally stated on the basis of the cumulative deaths and cumulative cases, ${ }^{3}$ as it ignores the fact that many of these patients are still active and have not reached to their end point yet. The trend of death to recovery ratio indicates that the case 


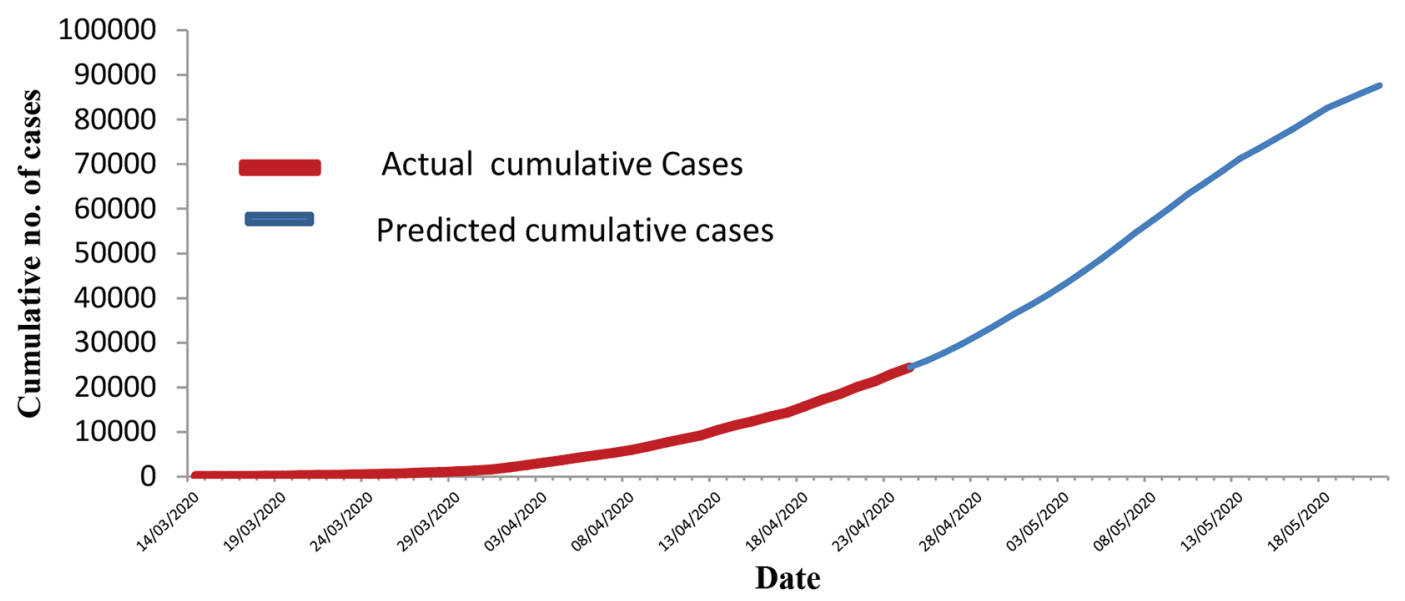

Fig. 1 Cumulative cases and trend.

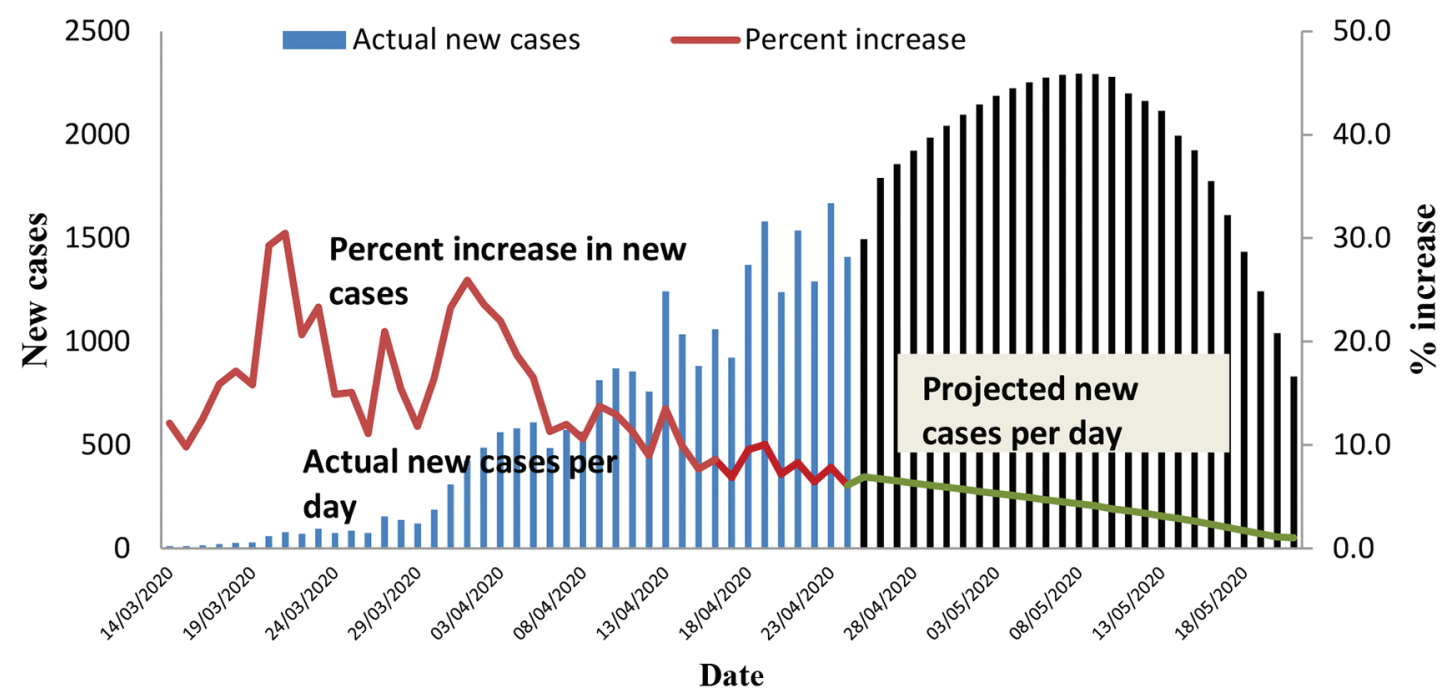

Fig. 2 New cases per day and the percentage increase over the cumulative on the previous day.

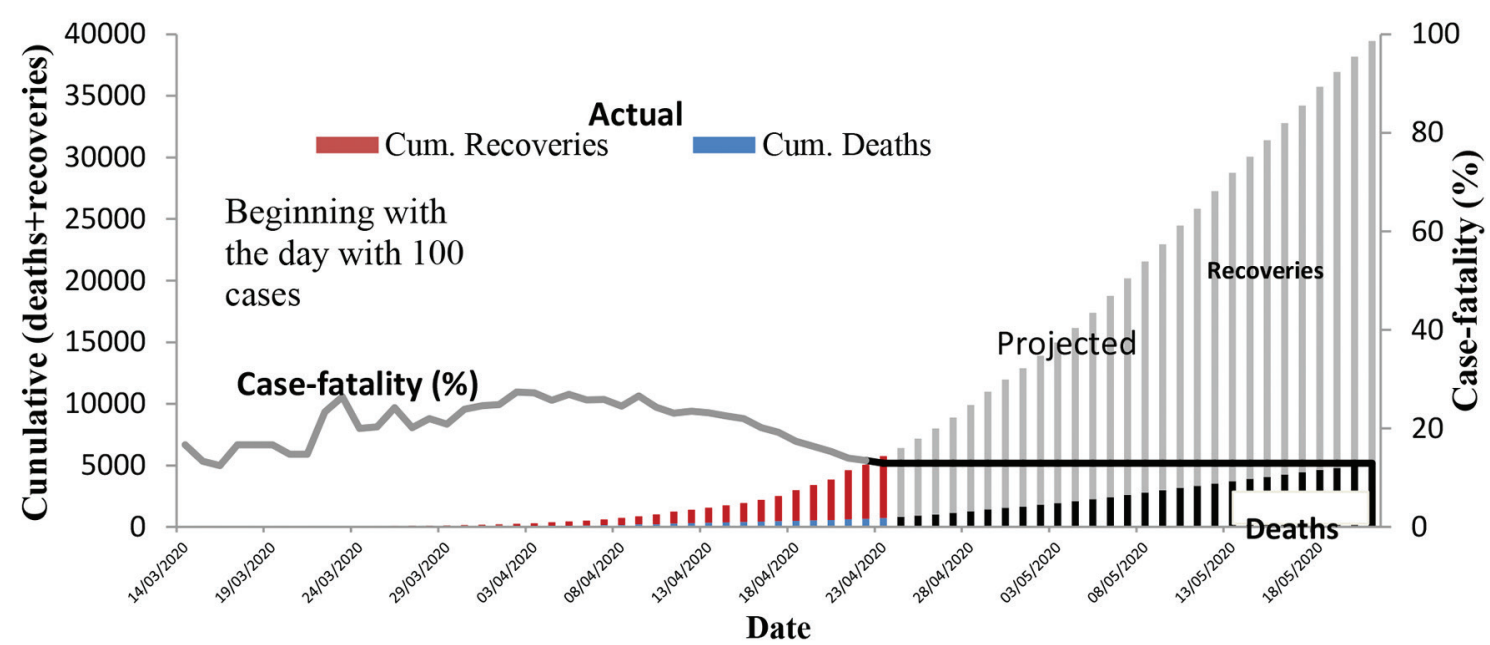

Fig. 3 Deaths and recoveries each day and the case fatality rate.

fatality, which at one point of time was $26 \%$, has come down to $13 \%$ by the end of the third week of April as our medical care system learns to manage these cases ( $\boldsymbol{- \text { Fig. }}$ 3). This decline could also be partially due to higher detection of cases at early stages, some even those without symptoms, as testing intensifies. These mild cases generally recover due to early care. The 
case fatality may come down to $10 \%$, even lower, in the course of time due to accrued lessons and emergence of plasma or other therapies but the present mortality pattern does not indicate a lower case fatality. Case fatality in China and some other countries is lower perhaps due to their better medical infrastructure and early detection.

Despite no target treatment available for COVID-19, it is strange that a large percentage of cases are recovering. ${ }^{4}$ This may be attributed to our in-built immunity and perhaps because the disease is mild in substantial percentage of cases. Low infections and mild disease in many cases also may be due to our better immunity levels. This point is not highlighted yet. Herd immunity is long way off and short-term strategies to raise immunity level through diet and yoga may provide further help.

With such widespread concern over this disease, it is interesting to compare the loss of life due to COVID-19 with the loss of life with injuries in India. With the crude death rate of 7.2 per thousand population in India and an estimated 138 crore population in $2020,{ }^{5}$ nearly 9.7 million deaths are likely to occur in India in the full year. According to the Global Burden of Disease 2016 estimate for India, more than 10\% of these deaths occurred due to injuries alone (of all kinds, including accidents, homicides, drowning, and animal bites). ${ }^{6}$ Thus, injuries are expected to take away nearly 1 million lives in 2020. Compare this with likely deaths by COVID-19. Moreover, most deaths by injuries in India are of young people whereas the toll by COVID-19 is mostly of old people, particularly those who have comorbid conditions, and are vulnerable to death anyway. In addition, a substantial saving of lives due to much less road and other injuries due to lockdown, may be more than the loss of life due to this disease.

\section{Conflict of Interest}

None declared.

\section{References}

1 Malani A, Gupta A, Abraham R. Why does India have so few Covid-19 cases and deaths? Quartz India. 16 April 2020. Available at: https://qz.com/india/1839018/why-does-indiahave-so-few-coronavirus-covid-19-cases-and-deaths/. Accessed April 24, 2020

2 Le Page M. Will the covid-19 coronavirus outbreak die out in the summer's heat? NewScientist. 12 Feb 2020. Available at: https://www.newscientist.com/article/2233249-will-thecovid-19-coronavirus-outbreak-die-out-in-the-summersheat/. Accessed April 25, 2020

3 Jayakumar PB. Coronavirus death rate in India 3.3\%, nearly 20 times less than global rateBusiness Today 18 April 2020. Available at: https://www.businesstoday.in/latest/trends/coronavirus-death-rate-india-3-3-percent-nearly-20-times-lessthan-global-rate/story/401389.html. Accessed April 19, 2020

4 Covid 19 India. Available at: https://www.covid19india.org/. Accessed April 25, 2020

5 India Population. Available at: http://www.populationu.com/ india-population. Accessed April 25, 2020

6 World Health Organization. Disease burden and mortality estimates: disease burden 2000-2016. Available at: https:// www.who.int/healthinfo/global_burden_disease/estimates/ en/index1.html. Accessed April 25, 2020 